Батыков Иван Владимирович

кандидат социологических наук, заведующий лабораторией социологической экспертизы Федерального научно-исследовательского социологического центра Российской академии наук

\section{ПРАВОВЫЕ ОСНОВЫ ОПРЕДЕЛЕНИЯ СРОКА ПОЛЕЗНОГО ИСПОЛЬЗОВАНИЯ ОБЩЕИЗВЕСТНЫХ ТОВАРНЫХ ЗНАКОВ}

Аннотация:

В статье предпринята попытка определения срока полезного использования общеизвестных товарных знаков в целях разрешения ситуации правовой неопределенности, в которой находятся общеизвестные товарные знаки по сравнению с обычными. Автор проводит логический анализ законодательства и решений государственных органов, по результатам которого можно говорить о том, что, несмотря на отсутствие ограничений длительности регистрации, срок полезного использования общеизвестного товарного знака не может быть признан неопределенным. Также предлагается исследование существующих правовых и экономических подходов к установлению срока полезного использования применительно к общеизвестным товарным знакам для выявления наиболее надежного подхода. На основе данных открытого реестра общеизвестных в Российской Федерации товарных знаков, публикуемого Роспатентом, рассчитывается минимальный срок полезного использования для рассматриваемого объекта. Отмечается, что средний срок составляет минимум 325 месяцев.

\section{Ключевые слова:}

общеизвестные товарные знаки; жизненный цикл продуктов, маркированных общеизвестными товарными знаками; коммерческая ценность общеизвестных товарных знаков; невозможность запланированного устаревания; стабильность отраслей функционирования; конкурентное преимущество; бессрочность контроля; минимальный срок полезного использования.
Batykov Ivan Vladimirovich

PhD in Social Science Chief of the Sociological Examination Laboratory, Federal Center of Theoretical and Applied Sociology of the Russian Academy of Sciences

THE LEGAL BASIS FOR DETERMINING THE USEFUL LIFE OF THE WELL-KNOWN TRADEMARKS

Summary:

The study attempts to determine the useful life of the well-known trademarks to eliminate the legal uncertainty of the well-known trademarks compared to the standard ones. The author carries out a logical analysis of the legislation and Russian state decisions resulted in the fact that despite the absence of restrictions on the duration of registration, the useful life of a wellknown trademark cannot be considered as uncertain. It is proposed to examine current legal and economic approaches to determining the useful life of the wellknown trademarks to identify the most reliable approach. The minimum useful life of the research subject is analyzed on the basis of the open catalogue of Russian well-known trademarks published by the Russian Federal Service for Intellectual Property (Rospatent). According to the results of the analysis, the average useful life of a well-known trademark in the Russian Federation is at least 325 months.

Keywords well-known trademarks, life cycle of well-known trademark products, commercial value of well-known trademarks, impossible planned obsolescence, stable areas, competitive advantage, perpetual control, minimum useful life.

Постановка проблемы. Срок полезного использования - одна из наиболее важных характеристик любого актива, определяющая как его ценность, так и границы связанной с этой ценностью ответственности собственника. Соответствующее определение вводится, например, в Налоговом кодексе РФ: «Сроком полезного использования признается период, в течение которого объект основных средств или объект нематериальных активов служит для выполнения целей деятельности налогоплательщика» [1]. Это же понятие в отношении нематериальных активов фригурирует и в регламентах финансовой отчетности - как в Положении по бухгалтерскому учету (далее - ПБУ), так и в международных стандартах финансовой отчетности (далее - МСФО). Согласно ПБУ, «сроком полезного использования является выраженный в месяцах период, в течение которого организация предполагает использовать нематериальный актив в целях получения экономической выгоды (или для использования в деятельности, направленной на достижение целей создания некоммерческой организации)» [2]. Согласно МСФО, «срок полезного использования - это: а) период, на протяжении которого, как ожидается, актив будет доступен для использования организацией; б) количество единиц продукции или аналогичных единиц, которые организация ожидает получить от использования актива» [3]. В бухгалтерской практике срок полезного использования товарного знака устанавливается исходя из длительности действия прав на него собственника и периода контроля над товарным знаком или на основе ожидаемого срока использования знака, в течение которого собственник предполагает получать экономические выгоды либо достигать некоммерческих целей [4]. Согласно НК РФ, «определение срока полезного 
использования объекта нематериальных активов производится исходя из срока действия патента, свидетельства и (или) из других ограничений сроков использования объектов интеллектуальной собственности в соответствии с законодательством Российской Федерации или применимым законодательством иностранного государства, а также исходя из полезного срока использования нематериальных активов, обусловленного соответствующими договорами» [5].

Для обычного товарного знака из приведенных определений обычно делаются простые и однозначные выводы: «Поскольку свидетельство выдается на срок 10 лет, то соответственно на этот же период устанавливается и срок полезного использования товарного знака» [6, с. 373]. Однако эти суждения совершенно неверны применительно к товарным знакам, признанным общеизвестными в Российской Федерации согласно ст. 1508 ГК РФ, - правовая охрана предоставляется общеизвестному товарному знаку бессрочно [7], таким образом, не требует продления. Следовательно, определение срока полезного использования на основе срока действия свидетельства осуществить невозможно. Значит, в отличие от обычных товарных знаков, общеизвестные оказываются в области правовой неопределенности.

В статье предпринята попытка решения данной проблемы на основе логического анализа законодательства и решений государственных органов с последующим статистическим исследованием сложившейся юридической практики. Сначала демонстрируется, что, несмотря на отсутствие ограничений длительности регистрации, срок полезного использования общеизвестного товарного знака не может быть признан неопределенным. Затем рассматриваются существующие правовые и экономические подходы к установлению срока полезного использования с акцентом на общеизвестных товарных знаках, определяется наиболее подходящий и надежный подход. В качестве итога на основе этого метода рассчитан минимальный срок полезного применения для общеизвестных в Российской Федерации товарных знаков.

1. Является ли срок полезного использования общеизвестных товарных знаков неопределенным? Прежде чем устанавливать срок полезного использования актива, необходимо убедиться в том, что он может быть определен исходя из объективных обстоятельств. Основные сомнения в такой возможности применительно к общеизвестному товарному знаку можно суммировать в следующем списке:

а) общеизвестный товарный знак представляет собой нематериальный актив, который не подлежит четко определяемому износу;

б) факторы износа не имеют однозначно оцениваемого действия, поскольку из истории известно большое количество обозначений, как используемых столетиями (банк Barclays, производитель алкоголя Bushmills, оружейная компания Beretta, Трехгорная мануфактура и т. п.), так и быстро прекращавших существование (характерный пример - игровые приставки Atari в США и Dendy в России);

в) срок действия защиты на общеизвестный в Российской Федерации товарный знак не ограничен законодательством.

Контраргументами к приведенным сомнениям могут служить следующие соображения.

А. Хотя нематериальный актив действительно не подлежит четко устанавливаемому износу, именно общеизвестный товарный знак представляет собой особый род актива, который по определению обладает высокой ценностью, целенаправленно созданной правообладателем. Следовательно, у правообладателей таких активов должно быть повышенное качество бизнеспланирования и управления, которое и позволяет адекватно прогнозировать функционирование общеизвестного товарного знака.

Б. Вариативность действия факторов износа наблюдается для любых объектов, по отношению к которым устанавливается срок полезного использования, в том числе фризических, поэтому учет погрешностей является естественной необходимостью при любых обстоятельствах. Как указано в МСФО, «неясность оправдывает осмотрительность при расчете срока полезного использования нематериального актива, но не оправдывает выбор нереалистично короткого срока» [8].

В. Бессрочность действия защиты на общеизвестный товарный знак не означает ее бесконечности. Так, по состоянию на сегодняшний день 4 из 198 общеизвестных знаков аннулированы, что составляет $2 \%$ - существенную величину. Положение о бессрочности правовой охраны также не может однозначно трактоваться как выводящее общеизвестные товарные знаки из-под действия статьи 1486 ГК РФ, которая предусматривает досрочное прекращение регистрации товарного знака вследствие его непрерывного неиспользования в течение 3 лет [9]. Хотя попытки применения данного положения к общеизвестным знакам не встречались в судебной практике, они теоретически возможны. Поскольку общеизвестный товарный знак является разновидностью товарных знаков вообще, статья 1486 распространяется на него по логике родовидовых отношений, ведь она содержит указания для любых товарных знаков, следовательно, и для общеизвестных.

Кроме того, в пользу определенности срока полезного использования общеизвестного товарного знака можно привести доказательства от противного. Предположим, что такой срок будет 
признан неопределенным. В данном случае оказывается применима норма НК РФ об амортизации: «По нематериальным активам, по которым невозможно определить срок полезного использования объекта нематериальных активов, нормы амортизации устанавливаются в расчете на срок полезного использования, равный 10 годам (но не более срока деятельности налогоплательщика)» [10]. Таким образом, общеизвестный товарный знак не просто приравнивается к обычному, для налогоплательщиков с небольшой продолжительностью деятельности срок полезного использования по нему может быть законно установлен меньше, чем для обычного товарного знака. Это представляло бы правовой парадокс, которого желательно избежать. Из этого следует необходимость признания срока полезного использования общеизвестного товарного знака в Российской Федерации определенным.

2. Способы установления срока полезного использования общеизвестного товарного знака. По требованиям МСФО при определении срока полезного использования нематериального актива учитываются многие фракторы [11]. Мы рассмотрели возможности их использования применительно к общеизвестным товарным знакам по порядку.

А. Предполагаемое использование общеизвестного товарного знака организацией и способность другой руководящей команды эффрективно управлять им. Данный фактор сугубо индивидуален и не может быть учтен для определения усредненной оценки по всей категории активов.

Б. Обычный жизненный цикл продукта относительно общеизвестного товарного знака, а также общедоступная информация о расчетных оценках срока полезного использования аналогичных активов, применяемых аналогичным образом. Жизненный цикл продуктов, маркированных общеизвестными товарными знаками, может существенно различаться, но в среднем он должен быть заведомо более длительным, чем у продуктов, маркированных обычными знаками. Поскольку общеизвестный знак представляет собой особо ценный актив, на его создание требуется значительно больше времени, соответственно, возрастает средний срок окупаемости инвестиций и возможного извлечения прибыли. Общедоступная информация о сроках полезного использования аналогичных активов содержится в открытом реестре общеизвестных в Российской Федерации товарных знаков Роспатента и может применяться для расчетов.

В. Техническое, технологическое, коммерческое и другие типы устаревания. Будучи нематериальным активом, связанным с существованием определенных образов в сознании потребителей, общеизвестный товарный знак не подлежит ни техническому, ни технологическому устареванию. Для них также характерно чрезвычайно замедленное коммерческое устаревание или даже возрастание их коммерческой ценности со временем в силу закономерностей выполняемых маркетинговых и рекламных функций. В.С. Никулина отмечает: «Выполнение товарным знаком рекламной функции может быть как основой для приобретения маркированной им продукцией определенного образа, а самим товарным знаком и его владельцем - деловой репутации, так и способом поддержания уже достигнутого восприятия данной продукции потребителями. Таким образом, товарный знак выполняет вышеуказанные функции за счет приобретенной самим обозначением репутации, тем самым обеспечивая постоянство или наращивание потребительской аудитории правообладателя, создавая для последнего преимущества перед его конкурентами» $[12$, c. 6]. Очевидно, что с точки зрения рационального ведения бизнеса конкурентное преимущество должно поддерживаться на существующем уровне и может быть утрачено не в силу запланированного устаревания, а только из-за неблагоприятной ситуации на рынке. Этот тезис доказывается опытом таких компаний, как Coca-Cola, McDonald's, IBM и др., коммерческая ценность широко известных товарных знаков которых со временем только повышается.

Г. Стабильность отрасли, в которой функционирует общеизвестный товарный знак, и изменения рыночного спроса на продукты или услуги, маркированные им. В силу того что для создания общеизвестного товарного знака необходимы длительная рекламная кампания и продвижение на рынке, устойчивость соответствующих отраслей должна быть выше средней. В эфемерных, нестабильных областях общеизвестные товарные знаки создать либо невозможно, либо чрезвычайно трудно.

Д. Предполагаемые действия реальных или потенциальных конкурентов в случае с общеизвестным товарным знаком являются существенно ограниченными. Так, в ст. 1508 ГК РФ установлено, что правовая охрана общеизвестного товарного знака распространяется также на товары, неоднородные с теми, в отношении которых он признан общеизвестным, если использование другим лицом этого товарного знака применительно к указанным товарам будет ассоциироваться у потребителей с обладателем исключительного права на общеизвестный товарный знак и может ущемить законные интересы такого обладателя [13]. Кроме того, предоставление правовой охраны любому другому товарному знаку может быть признано недействительным в течение всего срока действия его правовой охраны, если она была предоставлена позднее приоритета общеизвестного товарного знака иного лица [14]. Аналогичная по содержанию норма для обычного товарного знака дает добросовестному правообладателю только 5 лет на обнаружение имитаторов и оспаривание 
их регистрации в Роспатенте [15]. Благодаря данной защите попытки паразитировать на известном имени даже в самых отдаленных классах МКТУ могут быть пресечены, в силу чего ставятся жесткие рамки так называемому «размытию» товарного знака - одному из основных рисков для средств индивидуализации, признанных в международной юридической практике [16].

Е. Уровень затрат на поддержание и обслуживание общеизвестного товарного знака, требуемых для получения ожидаемых экономических выгод от этого актива, а также способность и готовность организации его обеспечить. В связи с тем что право на общеизвестный знак является констатацией существующей высокой степени информированности потребителей, для получения будущих экономических выгод не нужны никакие дополнительные вложения, это состояние представляет собой чистое конкурентное преимущество. Конечно, для его поддержания необходимы расходы, но их одновременный прямой учет для всей категории активов не представляется возможным.

Ж. Период контроля над общеизвестным товарным знаком не ограничен законодательством, хотя и не является бесконечным или неопределенным.

3. Зависимость срока полезного использования общеизвестного товарного знака от срока полезного использования других активов организации представляет собой индивидуальную переменную и не может быть применена ко всей категории активов.

Подводя итог, можно сказать, что из перечисленных факторов вытекает следующий порядок определения срока полезного использования общеизвестного товарного знака:

1) жизненный цикл продуктов, маркированных общеизвестными товарными знаками, является заведомо более длительным, чем маркированных обычными, при этом общедоступная информация о сроках использования этой категории активов содержится в открытом реестре общеизвестных в Российской Федерации товарных знаков Роспатента;

2) у общеизвестного товарного знака не может быть запланированного устаревания, актив может быть утрачен только в результате непредвиденной неблагоприятной ситуации на рынке;

3) стабильность отраслей, в которых функционирует общеизвестный товарный знак, должна быть выше средней;

4) предполагаемые действия реальных или потенциальных конкурентов в случае с общеизвестным товарным знаком в среднем более ограниченны, чем для обычных товарных знаков;

5) для получения будущих экономических выгод не требуется никаких дополнительных вложений, общеизвестный товарный знак представляет собой чистое конкурентное преимущество, хотя для его поддержания вложения необходимы;

6) период контроля над общеизвестным товарным знаком не ограничен законодательством.

В свою очередь У. Ансон в руководстве по управлению нематериальными активами Американской ассоциации юристов предлагает следующие подходы к определению срока полезного использования [17, р. 84-85]:

1) основанный на законе - используется срок действия защиты зарегистрированного права;

2) контрактный - применяется срок контрактных обязательств, обеспечивающих существование актива; функций.

3) функциональный - базируется на прогнозе длительности выполнения активом своих

4) технологический - включает прогноз устаревания технологий;

5) экономический - используются экономические прогнозы изменения ситуации;

6) аналитический - основан на статистике аналогичных объектов интеллектуальной собственности.

Из этого списка подходов первый не может быть применен в силу бессрочности защиты общеизвестного товарного знака, второй и четвертый нерелевантны природе актива, третий дает неограниченный срок полезного использования (в силу упоминавшейся рекламной функции, детерминирующей роль общеизвестного товарного знака как конкурентного преимущества). Экономический подход является зависимым от отраслей, а потому его применение к усредненной оценке срока для категории активов затруднено. Однако оставшийся шестой - аналитический подход может быть эффективно реализован в связи с тем, что Роспатент предоставляет полную информацию о таких характеристиках общеизвестных товарных знаков, как сроки регистрации и даты, с которых признается общеизвестность.

3. Расчет срока полезного использования по данным Роспатента. Прежде чем производить расчеты, мы рассмотрели структуру информации, предоставляемой Роспатентом по общеизвестным товарным знакам в реестре [18]. Каждая запись в нем включает следующие наиболее важные для нашей задачи поля данных:

1) регистрационный номер товарного знака в виде непрерывной возрастающей последовательности начиная с единицы;

2) дату вступления в силу решения о признании товарного знака общеизвестным;

3) дату, с которой товарный знак признан общеизвестным; 
4) сведения о правообладателях, в том числе о переходе прав;

5) данные о прекращении защиты товарного знака (в случае если она прекращена).

Прежде всего необходимо решить, как из этой информации могут быть извлечены сведения о сроке полезного использования актива. К такому сроку не может быть отнесено применение обозначения до даты его официального приоритета, даже если оно было тождественно зарегистрированному впоследствии общеизвестному товарному знаку. Дело в том, что такое обозначение до момента наступления общеизвестности имеет иную правовую природу и подлежит иной защите. Общеизвестность устанавливается на определенный момент (дату, с которой товарный знак признан общеизвестным), который может быть в прошлом по отношению к дате решения о признании общеизвестности. Поэтому дата административного решения также не может служить границей срока полезного применения: решение фиксирует уже состоявшееся использование общеизвестного товарного знака. Дата, с которой товарный знак признан общеизвестным, хотя прямо и не названа в качестве даты приоритета, но выполняет ее функцию (в частности, сопоставляется с датой приоритета обычных товарных знаков в ст. 1508 ГК РФ). Таким образом, именно эта дата может служить нижней границей для регистрируемых по данным Роспатента сроков полезного применения.

Учитывая бессрочность контроля над общеизвестным товарным знаком, верхней границей может считаться настоящее время для тех объектов, защита которых сохраняется, и дата аннулирования регистрации для тех, чья защита прекращена. К сожалению, при расчете по всему реестру эта граница будет давать заведомо заниженные показатели, в связи с тем что у недавно зарегистрированных общеизвестных товарных знаков адекватные сроки использования еще не накопились. Так, для общеизвестного товарного знака № 198 срок использования к 2018 г. составит менее 2 лет, что намного меньше фрормальных оценок, получаемых для обычных товарных знаков. При том что для продуктов, маркированных общеизвестными товарными знаками, характерен более длительный жизненный цикл.

Возникает необходимость ограничить расчеты наиболее релевантной выборкой из реестра. Относительно более высокая стабильность отраслей, в которых функционирует общеизвестный товарный знак, и ограниченность действий конкурентов свидетельствуют в пользу того, что выборку нужно осуществлять с первых регистрационных номеров и двигаться по восходящей. Как указано ранее, из-за невозможности запланированного устаревания прекращение использования общеизвестного товарного знака возможно в результате непредвиденных обстоятельств, таких как аннулирование. Поэтому представляется оправданным взять для расчета выборку записей реестра, которая предшествует первому зафиксированному случаю прекращения защиты общеизвестного товарного знака. Таковым является запись № 14. Следовательно, в выборку должны попасть первые 13 общеизвестных в Российской Федерации товарных знаков. Данные по ним приведены в таблице 1.

Таблица 1 - Выборка общеизвестных товарных знаков, отобранных до первого зафиксированного случая прекращения защиты общеизвестного товарного знака

\begin{tabular}{|c|c|c|c|}
\hline $\begin{array}{c}\text { Номер } \\
\text { общеизвестного } \\
\text { товарного знака }\end{array}$ & $\begin{array}{c}\text { Словесное } \\
\text { обозначение } \\
\text { на товарном знаке }\end{array}$ & $\begin{array}{c}\text { Дата, с которой } \\
\text { товарный знак признан } \\
\text { общеизвестным }\end{array}$ & $\begin{array}{c}\text { Срок использования } \\
\text { на сентябрь } 2018 \text { г., } \\
\text { мес. }\end{array}$ \\
\hline 1 & Известия & 31.12 .1992 & 309 \\
\hline 2 & Уралмаш & 31.12 .1977 & 489 \\
\hline 3 & Ява & 31.12 .1989 & 345 \\
\hline 4 & Здоровье & 01.02 .1992 & 320 \\
\hline 5 & Coca-Cola & 01.01 .1996 & 273 \\
\hline 6 & Васпуракан & 30.11 .1990 & 334 \\
\hline 7 & Наири & 30.11 .1990 & 334 \\
\hline 8 & Ахтамар & 30.11 .1990 & 334 \\
\hline 9 & Отборный & 30.11 .1990 & 334 \\
\hline 10 & Двин & 30.11 .1990 & 334 \\
\hline 11 & Арарат & 30.11 .1990 & 334 \\
\hline 12 & Клинское & 31.12 .1999 & 225 \\
\hline 13 & Ферейн & 31.12 .1996 & 261 \\
\hline \multicolumn{3}{|l|}{ Среднее } & 325 \\
\hline
\end{tabular}

Полученная величина в 325 месяцев является нижней границей среднего срока полезного использования общеизвестного в Российской Федерации товарного знака, поскольку с течением времени этот срок будет увеличиваться. Вместе с тем установленная нижняя граница хорошо согласуется с требованиями, предъявляемыми к обсуждаемому показателю: с одной стороны, он существенно превышает сроки полезного применения для обычных товарных знаков, с другой соответствует реалиям российской экономической практики. 
Выводы. Анализ существующих подходов к определению срока полезного использования нематериальных активов показал, что наиболее адекватным решаемой нами задаче является аналитический расчет, осуществляемый по данным открытого реестра общеизвестных в РФ товарных знаков, публикуемого Роспатентом. При этом учитывались такие фракторы, как более длительный жизненный цикл продуктов, маркированных общеизвестными товарными знаками; невозможность запланированного устаревания; относительно высокие стабильность отраслей, в которых функционирует общеизвестный товарный знак, и ограниченность для действий конкурентов; характер общеизвестного товарного знака как непосредственного конкурентного преимущества; бессрочность контроля над общеизвестным знаком. По итогам исследования средний срок полезного применения общеизвестного в России товарного знака составляет минимум 325 месяцев.

\section{Ссылки:}

1. Налоговый кодекс РФ [Электронный ресурс] : в ред. от 3 авг. 2018 г. П. 1 ст. 258. Доступ из справ.-правовой системы «КонсультантПлюс».

2. Учет нематериальных активов [Электронный ресурс] : положение по бухгалтерскому учету (ПБУ 14/2007) : в ред. от 16 мая 2016 г. П. 25. Доступ из справ.-правовой системы «КонсультантПлюс».

3. Нематериальные активы [Электронный ресурс] : международный стандарт фринансовой отчетности (IAS) 38 : в ред. от 27 июня 2016 г. П. 8. Доступ из справ.-правовой системы «КонсультантПлюс».

4. Учет ... П. 26

5. Налоговый кодекс .... П. 2 ст. 258.

6. Иванов И.В., Баранов В.В. Финансовый менеджмент: стоимостный подход. М., 2007.

7. Гражданский кодекс РФ [Электронный ресурс] : в ред. от 23 мая 2018 г. П. 2 ст. 1508. Доступ из справ.-правовой системы «КонсультантПлюс».

8. Нематериальные активы ... П. 93.

9. Гражданский кодекс ... П. 1 ст. 1486.

10. Налоговый кодекс ... П. 2 ст. 258

11. Нематериальные активы ... П. 90.

12. Никулина В.С. Правовая защита товарного знака и борьба с недобросовестной конкуренцией. М., 2015.

13. Гражданский кодекс ... П. 3 ст. 1508.

14. Там же. Подп. 4 п. 2 ст. 1512.

15. Там же. Подп. 2 п. 2 ст. 1512.

16. Невзоров И.В. Скрытые возможности правообладателя: о защите различительной способности товарного знака от «размытия» // Судья. 2016. № 2. С. 26-29.

17. Anson W. The Intangible Assets Handbook. Chicago, 2007.

18. Открытые реестры [Электронный ресурс] // Федеральный институт промышленной собственности : официальный сайт. URL: http://www1.fips.ru/wps/portal/Registers (дата обращения: 08.10.2018).

\section{References:}

Anson, W 2007, The Intangible Assets Handbook, Chicago.

Ivanov, IV \& Baranov, VV 2007, Financial Management: a Cost Approach, Moscow, (in Russian).

Nevzorov, IV 2016, 'Hidden Possibilities of the Right Holder: on Protection of Distinctive Ability of the Trademark from "Blur-

ring"', Sud'ya, no. 2, p. 26-29, (in Russian).

Nikulina, VS 2015, Trademark Legal Protection and the Fight against Unfair Competition, Moscow, (in Russian). 